\title{
Teaching to Self-Regulate in Mathematics: A Quasi-Experimental Study with Low-Achieving Elementary School Students
}

\section{Enseñanza de la autorregulación en Matemáticas: estudio cuasiexperimental con escolares de bajo desempeño}

\author{
Daniel Trias Seferian (1) https://orcid.org/0000-0003-1274-9134 \\ Cindy Mels Auman (1) https://orcid.org/0000-0001-5168-8114 \\ Juan Antonio Huertas Martínez (2) https://orcid.org/0000-0002-1518-8398 \\ (1) Universidad Católica del Uruguay \\ (2) Universidad Autónoma de Madrid \\ (Received: April 1st, 2019; accepted for publishing: August 13, 2019) \\ How to cite: Trias, D., Mels, C., \& Huertas, J. A. (2021). Teaching to self-regulated in Mathematics: A quasi-experimental study with \\ low-achieving elementary school students. Revista Electrónica de Investigación Educativa, 23, e02, 1-13. \\ https://doi.org/10.24320/redie.2021.23.e02.2945
}

\begin{abstract}
Teaching students to self-regulate enhances their mathematics performance, yet few studies have investigated the long-term differential impact of particular self-regulation strategies specifically for lowachieving students. This quasi-experimental study evaluates the effect of teaching different selfregulation strategies on mathematical problem solving in low-achieving students. The participants were 69 sixth-grade elementary school students randomly assigned to one of three experimental groups (and taught predominantly cognitive, metacognitive or volitional strategies, while verifying intervention fidelity) or a control group for 16 sessions. Mathematical problem-solving skills were evaluated prior to the intervention, upon completion, and two months later. While all three intervention groups obtained significantly better results compared to the control group immediately after the intervention, volitional and metacognitive strategies showed the strongest and most lasting positive effects. We conclude that low-achieving students could benefit from learning self-regulation strategies, particularly when these strategies take into account the affective and motivational dynamics of learning.
\end{abstract}

Keywords: mathematics, metacognition, motivation, emotion, learning.

\section{Resumen}

Enseñar autorregulación impacta positivamente en el desempeño en matemáticas. Pocos estudios han investigado ese impacto en el largo plazo, específicamente en estudiantes de bajo rendimiento. Este estudio cuasi-experimental evalúa los efectos de enseñar diferentes estrategias de autorregulación en la resolución de problemas matemáticos, en estudiantes de bajo rendimiento. Participaron 69 estudiantes de sexto grado de escuela primaria, asignados aleatoriamente a tres condiciones experimentales (estrategias cognitivas, metacognitivas o volitivas, verificando la fidelidad de la intervención) o grupo control. La resolución de problemas matemáticos fue evaluada previamente, al finalizar y 2 meses después de la intervención. Los tres grupos de intervención obtuvieron mejores resultados comparados con el control, finalizada la intervención. Las estrategias volitivas y metacognitivas mostraron los efectos positivos más fuertes y duraderos. Se concluye que estudiantes con bajo desempeño pueden beneficiarse de la enseñanza de estrategias de autorregulación, especialmente al considerar las dinámicas afectivas y 
motivacionales del aprendizaje.

Palabras clave: matemáticas, metacognición, motivación, emoción, aprendizaje.

\section{Introduction}

It is widely accepted that self-regulation strategies impact academic achievement (Cleary \& Kitsantas, 2017). Therefore, an important challenge for the field of Self-Regulated Learning (SRL) regards its implementation in natural educational settings through tangible and effective interventions. The fact that acquiring mathematical skills is a common problem identified in education systems throughout the world poses an opportunity for investigating the effectiveness of SRL interventions. A significant number of Uruguayan students fail to achieve basic mathematical competencies throughout their education. For example, 52\% of Uruguayan 15-year-olds participating in PISA 2015 were unable to meet the baseline proficiency level (level 2) as defined by the Organization for Economic Cooperation and Development (OECD, 2016). Learning mathematics is at the heart of several education systems and instructional practices could take advantage of the growing body of evidence regarding SRL and its positive impact on problem solving and achievement (Dignath \& Büttner, 2008; Taylor et al., 2017).

SRL implies a series of processes by which learners personally activate and sustain cognition, emotions and behavior in a systematic way, allowing them to attain their goals (Greene, 2018). Studies on SRL of mathematics have focused on cognitive and metacognitive processes, as summarized in Zimmerman's cyclical phases model (de Corte et al., 2011; Panadero, 2017). As such, the ability to self-regulate manifests as the use of strategies to plan, supervise and control task execution, and the evaluation of these processes and their results (Zimmerman, 2000). The imbalance between these elements is particularly salient among students who experience difficulty learning mathematics (Schoenfeld, 1992).

Despite the traditional emphasis in the field on cognitive and metacognitive SRL strategies, the emotional dynamics of learning are also considered paramount for educational studies and practice, as expressed in several theoretical models of self-regulation (Baars et al., 2017; Ben-Eliyahu, 2019; Panadero, 2017). Nonetheless, the specific use of these strategies has not received sufficient consideration in studies on self-regulation, and even less so in teaching interventions to promote SRL (Donker et al., 2014; Heirweg et al., 2019; Schukajlow et al., 2017; Tzohar-Rozen \& Kramarski, 2018).

The regulation of motivation, emotion and behavior lies at the core of volitional strategies for learning (Corno, 2001). It is not quite clear how exactly volitional processes influence effort regulation and academic performance (Kim \& Bennekin, 2013). However, there is no doubt that emotions play a part in learning, as is shown in frequent observations of frustration and anger during the process (Op'tEynde et al., 2006). Changes in emotions could result in systematic changes in SRL and performance (Schukajlow \& Racoczy, 2016). Interventions aiming to promote SRL have progressively included cognitive, metacognitive, and volitional strategies, leading to questions regarding their particular role in the acquisition of mathematical problem solving skills.

\subsection{Self-regulated learning in mathematics}

Self-regulation is considered an essential component of mathematical competence and therefore should be considered an objective in teaching mathematical problem solving or MPS (de Corte et al., 2011). MPS is conceived of as an active process involving construction of meaning, comprehension, and problem solving (Butler et al., 2005), which enables adaptation to new contexts and requires flexible, creative, and subjectively constructed knowledge, particularly in the case of low-achieving students (Butler et al., 2005). 
Teaching students to self-regulate seems particularly effective for mathematics performance when applied in elementary school, with an effect size of $d=1.00$ reported by Dignath et al. (2008), largely surpassing the threshold of $d=.40$ suggested by Hattie (2009) for visible effects upon academic performance. The effect is amplified when instruction entails or encourages motivational strategies, a component that has however been addressed by few studies (Dignath \& Büttner, 2008).

The final stages of primary education have been considered a critical moment for the development of specific attitudes and emotions towards mathematics, making it a particularly interesting target for intervention (Chatzistamatiou et al., 2015; Tzohar-Rozen \& Kramarski, 2014). As a result, addressing motivation and emotion regulation strategies at this particular time in students' educational trajectory could be relevant for promoting learning.

\subsection{SLR in low-achieving students}

Low and high-achieving students differ in how they self-regulate their learning (Harding et al., 2019; Otto \& Kistner, 2017). For example, low-achieving students report higher levels of volitional inhibition and are more affected by worries and unsettled by failure (Kazén et al., 2008). Task evasion, erroneous task analysis, limited planning, confined or faulty monitoring, reduced flexibility, and elevated stress and anxiety are more frequently observed in students with learning difficulties (Butler \& Schnellert, 2015; Schoenfeld, 1992). Some of these observed differences between low and high-performing students' learning may be induced by differential levels of previously acquired knowledge, considered to play an important role in SRL. Indeed, while students with limited previously established mathematical knowledge seem to benefit from domain-specific instruction when evaluated by tasks that require minimal transfer, their performance is poorer in tasks requiring a transfer of learning (Kramarski et al., 2013).

Most studies of SRL interventions have shown particular outcomes for low-achieving students (Dignath \& Büttner, 2008). It has been suggested by some authors that teaching SRL strategies could significantly benefit students who perform poorly in mathematics (Bishara, 2016; Butler et al., 2005; Donker et al., 2014; Kramarski et al., 2013), particularly while helping them construct metacognitive knowledge, deal with frustration and develop impulse control (Butler \& Schnellert, 2015). In particular, such interventions appear to favor poorly motivated students and those at risk for dropping out (Vandevelde et al., 2017). Nonetheless, to date the link between volitional control strategies and learning has hardly been investigated in elementary school students performing poorly in mathematics (de Corte et al., 2011; Dignath et al., 2008; Dörrenbächer \& Perels, 2015; Tzohar-Rozen \& Kramarski, 2014).

\subsection{Teaching SRL in a school setting}

There is a strong consensus that SRL interventions should be contextualized within specific domains, in an environment that entails and promotes the use and transferability of self-regulating strategies (Dignath et al., 2008). Naturalistic classroom observations have shown that the best results are achieved by teaching strategies explicitly; nonetheless, most teaching occurs implicitly (Dignath \& Büttner, 2018). As teaching SRL is beneficial for students' performance, there is a need to further expand our knowledge on how best to establish SRL instruction in settings more closely associated with a natural school situation (Dignath \& Büttner, 2018).

Although more pronounced in laboratory-like conditions, significant effects from SRL interventions in the classroom have been established by several studies (Dignath \& Büttner, 2008; Perels et al., 2009). For example, Leidinger and Perels (2012) and Yidizli and Saban (2016) have reported improvements in students' mathematical performance after they were explicitly taught metacognitive strategies for selfregulation. Regarding the volitional component of SRL, Tzohar-Rozen and Kramarski (2014) observed positive effects on mathematical performance from an intervention that addressed the emotional aspects of self-regulation with 10 and 11 -year-olds. The authors found similar results with reference to mathematical problem solving when comparing students taught metacognitive strategies and those who 
had received instruction centered on motivation and emotion regulation (Tzohar-Rozen \& Kramarski, 2014, 2018).

The question remains, however, as to which type of SRL instruction provides the most significant results within a natural context, including for low-achieving students, in the long term (Donker et al., 2014). A meta-analysis performed by de Boer et al. (2018) found that teaching metacognitive strategies slightly increases performance in the long term, compared to the immediate intervention effect. Evidence on the outcome of volitional strategies, however, did not indicate solid improvement. Furthermore, considering the multiple processes involved in SRL, interest has arisen in researching the results that can be achieved by combining several SRL strategies in particular groups of students, in order to better understand who benefits from which strategies and to what extent (Schwinger \& Otterpohl, 2017).

Boekaerts (1999) hierarchically organizes self-regulatory processes in three layers: regulation of processing modes (choice of cognitive strategies, favoring the organization of tasks), regulation of the learning process (metacognitive skills and strategies), and regulation of the self (attention, motivation and affect). This last mode involves volitional strategies, which include controlling incentives, increasing effort and motivation, shutting out negative emotions and controlling one's impulses (Corno, 2001; Kuhl et al., 2014). Self-regulation strategies have increasingly been addressed in recent years, particularly in relation to emotion regulation (Ben-Eliyahu, 2019; Schlesier et al., 2019). Nonetheless, the particular use of these strategies has not been taken into sufficient consideration in studies of self-regulation, and even less so in teaching interventions to promote SRL (Donker et al., 2014; Schukajlow et al., 2017; Siddiqui \& Ventista, 2018; Tzohar-Rozen \& Kramarski, 2018). However, self-regulation strategies can be taught through direct instruction, modeling, and shared and autonomous work (Dignath \& Büttner, 2018).

The aim of this study is to evaluate the differential intervention effects of three strategies for SRL on MPS in low-achieving sixth-grade elementary school students, with the intervention setting approximating the daily classroom context in mathematics classes. The main research question focuses on determining the unique effects of teaching cognitive, metacognitive, and volitional strategies on MPS in this particular population, immediately after completing the intervention and two months afterwards (follow-up test).

\section{Method}

The current study employs a quasi-experimental pre-post design with a control group (Montero \& León, 2007). The independent variable under consideration is SRL teaching in three randomly assigned conditions - cognitive, metacognitive or volitional - and the dependent variable is the participants' score on a mathematical problem-solving test.

Participants. The sample was drawn from a pool of 305 sixth-grade students from six elementary schools in Montevideo, Uruguay, who participated in a Mathematical Problem-Solving Test (MPST), obtaining a mean of 17.52 (SD = 9.03). Students scoring below the 40th percentile were initially considered to be lowachieving. Students diagnosed with mathematical learning difficulties, severe sensory problems or behavioral problems, or who were receiving psychopedagogical, psychological and/or psychiatric treatment were excluded from the sample. The resulting list of 69 students was validated by their teachers who further identified them as low-achievers. Two participants withdrew from the sample, bringing the sample size down to $n=67$, all of whom attended at least $70 \%$ of all sessions. These students were randomly assigned to one of three experimental conditions: instruction of cognitive $(n=$ 15), metacognitive ( $n=16)$ or volitional $(n=16)$ strategies for SRL. Each condition was executed in smaller working groups consisting of three or four students or a control group $(n=21)$. No significant differences were found between the experimental conditions with respect to attendance, as verified by ANOVA ( $F(2)$ $=.72, p=.49)$.

Participants' ages varied from 11 years 2 months to 12 years 4 months and 56.7\% (38) were male. The mean average grade obtained for mathematics during the fifth grade was 7.15 (SD =1.44), on a scale 
from 0 to 12 (5 being the minimum for grade promotion). The sample mean for MPS at baseline was $14.21(\mathrm{SD}=7.16)$.

Instruments. The MPST evaluates competence in correctly solving mathematical problems aligned with the school curriculum, implying the adequate mobilization of knowledge, procedures, algorithms and strategies involved in MPS. The test was designed for the purpose of this study, based on tasks with a multiplicative structure (see Table I), as addressed by the national curriculum (Pena, 2005) and in consultation with expert teachers regarding its adequacy for evaluating their courses. Consequently, the items included in the test concerned mathematical problems similar to those addressed in the intervention. A team of two experts prepared and corroborated four comparable versions of the test consisting of 14 similarly-structured items or tasks that evaluated the mathematical problem-solving competencies required to tackle them.

The test required students to read each task, show the necessary working and give the final answer within a total of 40 minutes. Each task was scored from 0 to 3, depending on the proposed working and the final result, the sum of which provided the total test result (from 0 to 42). Based on our original sample pool $(n=305)$, the test's internal consistency reached $a=.82$. Confirmatory factor analysis based on these same data established a model consisting of a single dimension with acceptable goodness of fit $(\mathrm{GFI}=0.911)$ and root mean square error of approximation (RMSEA = 0.068) (Hu \& Bentler, 1999).

MPS test results in our study sample correlated positively and significantly with teacher-assigned grades in mathematics $(r=.31, p<.05)$, supporting the test's criterion validity.

Table 1. Examples of problems included in the mathematical test and the intervention

6 - A truck weighing 4,000 kilos is transporting 325 boxes of apples and 125 boxes of bananas. Each box filled with apples weighs 38 kilos and each box filled with bananas weighs 22 kilos. How many kilos is the truck transporting?

9 - Pablo is taking nine empty plastic bottles to be recycled. Two are soda bottles, and the remaining seven are mineral water bottles. He goes four times a day, each time taking the same number of bottles. How many bottles would he have taken in total for recycling in two weeks?

Procedure. Following institutional authorization from the participating schools, the MPST was collectively administered at baseline (MPS 1 ) to all sixth-grade students enrolled in the schools. The teachers informed the researchers which students they considered low-achieving in mathematics and provided their students' fifth-grade average mathematics grade points to the researchers. Based on these sources of information, participants for the intervention were selected and an informed consent form was sent out to their families.

Once all consent forms had been received, the 16 intervention sessions were conducted three times a week over two months, in the second semester of the school year. In all conditions the same mathematical problems were addressed using an identical sequence yet varying the content of the feedback delivered by implementers, based on the script assigned to them. Each intervention implementer worked in subgroups of four students, following one of the three scripts, outside the classroom. All group sessions were audio-recorded, which allowed the main researchers to evaluate the reliability of the implementation. Meanwhile, the students from the control group maintained regular classwork with their teachers.

The MPST was administered immediately after terminating the intervention (MPS2) and two months later (MPS 3 ). The scoring of the MPST occurred blinded from intervention conditions.

Intervention. Throughout 16 sessions, each lasting approximately 40 minutes, SRL strategies were taught through direct instruction, modeling and feedback to the participants, following a fixed sequence 
that involved solving four increasingly difficult mathematical problems. In each session, the first task was solved by the intervention implementer using direct instruction and modeling, the second by working in pairs, the third autonomously, and the fourth by one of the participants thinking aloud. All tasks entailed multiplicative structures, comparable to those addressed by the curriculum as implemented in Uruguayan schools (Pena, 2005; Picaroni \& Loureiro, 2010).

Each intervention group followed one of three scripts, each one corresponding to a particular "layer" as proposed in Boekaerts' (1999) model. Each script contained explicit strategies to be used and modeled by the intervention implementer and considered during feedback (Table II).

Table 2. Scripts used in the intervention groups (direct instruction, modeling, and feedback)

\begin{tabular}{|c|c|c|}
\hline Cognitive script (CS) & Metacognitive script (MCS) & Volitional script (VS) \\
\hline $\begin{array}{l}\text { Specific knowledge for solving } \\
\text { mathematical problems } \\
\text { + cognitive strategies }\end{array}$ & $\begin{array}{l}\text { Specific knowledge for solving } \\
\text { mathematical problems } \\
\text { + cognitive strategies } \\
\text { + metacognitive strategies }\end{array}$ & $\begin{array}{l}\text { Specific knowledge for solving } \\
\text { mathematical problems } \\
\text { + cognitive strategies } \\
\text { + volitional strategies }\end{array}$ \\
\hline $\begin{array}{l}\text { Description } \\
\text { Promotes cognitive strategies } \\
\text { closely related to MPS, with a } \\
\text { focus on task organization, such } \\
\text { as reading the task, } \\
\text { concentrating on the question or } \\
\text { problem, identifying relevant } \\
\text { facts, and stepwise problem } \\
\text { solving. }\end{array}$ & $\begin{array}{l}\text { Description } \\
\text { Expands the CS by including the } \\
\text { following metacognitive } \\
\text { strategies: planning (task analysis, } \\
\text { imagining a plan), supervision } \\
\text { (monitoring the action, describing } \\
\text { one's activities), and evaluation } \\
\text { (of the product and the process). }\end{array}$ & $\begin{array}{l}\text { Description } \\
\text { Adds volitional strategies to the } \\
\text { CS: enhancing effort and } \\
\text { concentration, disconnecting } \\
\text { from negative emotions, impulse } \\
\text { control, maintaining positive } \\
\text { affect. }\end{array}$ \\
\hline $\begin{array}{l}\text { Examples* } \\
\text { "How about reading the problem } \\
\text { again?" } \\
\text { "What is the assignment asking } \\
\text { for?" "Focus on the question." }\end{array}$ & $\begin{array}{l}\text { Examples } \\
\text { Planning: "Let's see what it's } \\
\text { about... it looks similar to what } \\
\text { we practiced yesterday. Let's plan, } \\
\text { we will lay out how we can solve } \\
\text { this problem." } \\
\text { Supervision and control: "Tell us } \\
\text { what you are doing, so we can } \\
\text { figure out what you are thinking. } \\
\text { It would be practical to stop and } \\
\text { revise." } \\
\text { Evaluation: "Let's evaluate what } \\
\text { we have been doing..." }\end{array}$ & $\begin{array}{l}\text { Examples } \\
\text { Control of incentives: "Remember } \\
\text { that the work you are doing now } \\
\text { will make you learn." } \\
\text { Disconnecting from negative } \\
\text { emotions: "Don't worry about } \\
\text { that..." } \\
\text { Relax: "Better loosen up a little." } \\
\text { Boost concentration: "I have to be } \\
\text { more alert." } \\
\text { Maintaining positive emotions: } \\
\text { "I'm already closer, I can get this." } \\
\text { Impulse control: "Wait a little..." }\end{array}$ \\
\hline
\end{tabular}

*Selection of example phrases used by the intervention implementers.

The Cognitive Script (CS) promoted cognitive strategies closely related to MPS, with a focus on task organization (de Boer et al., 2018). The metacognitive script (MCS) expanded the CS by including metacognitive strategies regarding the planning, supervision and evaluation of the task, as contemplated in Zimmerman's cyclical phases model (2000). The Volitional Script (VS) added volitional strategies (addressing motivation regulation, emotion regulation, and impulse control) to the CS (Baez-Estradas \& Alonso-Tapia, 2017). 
Intervention fidelity. Prior to the study, a pilot intervention was performed with 12 low-achieving students, allowing experts to test and approve the adequacy of each script. Subsequently, eight advanced psychopedagogy students were randomly assigned a script and trained as intervention implementers. Training involved analyzing situations recorded during the pilot study and practicing applying the script by proposing concrete approaches. Implementers were supervised and monitored through meetings with the first author after the first and third session and they completed a self-assessment form after each session.

All 16 sessions took place as planned in all groups, both in terms of frequency and duration. Compliance with the assigned scripts was evaluated for all intervention subgroups after completion of all 16 sessions (Greene, 2015). Verbalizations of each implementer were categorized by two independent referees as either cognitive, metacognitive or volitional control messages in a sample of two sessions. Interrater reliability reached a Cohen's kappa value of .88. Based on these analyses, at least $50 \%$ of all recorded verbal interactions corresponded with the intended script, confirming intervention fidelity.

Hypothesis. It is expected that those who were taught metacognitive and volitional strategies will exhibit improved MPS ability compared to control and cognitive intervention group students, as they hypothetically develop strategies to adequately address mathematical problems in a flexible and autonomous manner, allowing students to solve problems with less need for scaffolding and producing deeper and transferable learning. Moreover, we anticipate that these effects will remain two months after the intervention is complete.

Data analysis. Initial MPS 1 results of all groups were compared using ANOVA. The effect of experimental conditions was analyzed with ANCOVA, including MPS 2 and MPS 3 as independent variables and MPS 1 as a covariable (Huck \& Melean, 1975). The authors established $p<.05$ as the level of significance for the interpretation of tested comparisons. Cohen's $d$ was used as an indicator of effect size of group differences. SPSS version 18 was used for all analyses.

\section{Results}

As shown in Table III, all experimental and control groups have comparable MPS values at baseline, as no statistically significant differences are found at MPS ${ }_{1}$ across groups $(F(3,63)=1.12, p=.35, \eta 2=.05)$.

Table 3. Mean and standard deviation of MPS across experimental/control groups

\begin{tabular}{cccc}
\hline \multirow{2}{*}{$\begin{array}{c}\text { Group } \\
\text { Condition }\end{array}$} & MPS & MPS $_{2}$ & MPS $_{3}$ \\
\cline { 2 - 4 } & $M(S D)$ & $M(S D)$ & $M(S D)$ \\
\hline CG $^{1}$ & $14.29(7.54)$ & $10.10(6.28)$ & $9.00(5.63)$ \\
CS $^{2}$ & $12.80(6.73)$ & $16.27(8.57)$ & $13.27(9.00)$ \\
MCS $^{3}$ & $12.40(8.17)$ & $18.40(8.44)$ & $16.53(6.01)$ \\
VS $^{4}$ & $16.62(5.80)$ & $23.38(7.77)$ & $21.06(6.15)$ \\
\hline
\end{tabular}

${ }^{1}$ Control Group, $n=21 ;{ }^{2}$ Cognitive Script, $n=15 ;{ }^{3}$ Metacognitive Script, $n=15$;

${ }^{4}$ Volitional Script, $n=16$.

At the end of the intervention, MPS 1 was found to be significant as a covariable, $F(1,62)=75.61, p<.01$, $\eta 2=.55$. Group condition had a significant main effect on MPS, $F(3,62)=17.84, p<.01$. Effect sizes (Cohen's d) for all comparisons are presented in Table IV. Effects are significant for MPS 2 in all intervention groups. The group working from the volitional script obtained the largest effect sizes, followed by the MCS, and finally the CS group, yet all had a significantly higher mean MPS2 score than the control group. 
At two months post-intervention, similar comparisons were run, again showing a significant effect of MPS 1 on outcomes $\left(\mathrm{MPS}_{3}\right), F(1,49)=44.66, p<.01, \eta 2=.48$. Group condition significantly affected $\mathrm{MPS}_{3}$ results, $F(3,49)=6.32, p<.01$. The MCS and VS groups maintained improved MPS scores at MPS differing significantly from control group scores, with the VC group obtaining the highest scores (Table IV). On the other hand, the CS group mean did not differ significantly from the control group mean MPS.

Table 4. Effect sizes for group comparisons (Cohen's d)

\begin{tabular}{cl|c|c|c|c}
\hline & $\begin{array}{c}\text { Volitional } \\
\text { Script }\end{array}$ & $\begin{array}{c}\text { Metacognitive } \\
\text { Script }\end{array}$ & $\begin{array}{c}\text { Cognitive } \\
\text { Script }\end{array}$ & Control \\
\hline \multirow{2}{*}{ VS } & $\mathrm{MPS}_{2}$ & & 0.61 & 0.87 & $1.91^{* *}$ \\
& $\mathrm{MPS}_{3}$ & & 0.74 & $1.02^{* *}$ & $2.06^{* *}$ \\
$\mathrm{MCS}$ & $\mathrm{MPS}_{2}$ & & & 0.25 & $1.14^{* *}$ \\
& $\mathrm{MPS}_{3}$ & & & 0.43 & $1.30^{* *}$ \\
\multirow{2}{*}{$\mathrm{CG}$} & $\mathrm{MPS}_{2}$ & & & & $0.84^{* *}$ \\
& $\mathrm{MPS}_{3}$ & & & & 0.59 \\
\hline
\end{tabular}

${ }^{* *} p<.01$

\section{Discussion}

Using an experimental design, this study aimed to evaluate the impact that teaching particular strategies for SRL has on mathematical problem solving in low-achieving sixth-grade elementary school students. Although tested in a small sample, all three intervention strategies were associated with improvements in MPS, yet the strongest effects were found for the instruction of volitional strategies - in combination with cognitive strategies - followed by the instruction of combined metacognitive and cognitive strategies, both immediately after the intervention and at two months post-intervention. The intervention that only taught cognitive strategies produced the smallest, yet still positive, effects on MPS immediately after the intervention, and ceased to be effective two months later. These findings confirm our initial hypotheses, based on the premise that transfer of knowledge is encouraged when metacognitive or volitional strategies are involved, on top of cognitive strategies, supporting the need to combine strategies in order to promote SRL (Dignath et al., 2008).

Our observations are consistent with studies that show the positive impact of SRL strategies on academic outcomes, particularly in mathematics and at elementary school level (Dignath \& Büttner, 2008; Dignath et al., 2008), providing further evidence of the influence of self-regulation on academic achievement and the malleability of SRL. Our findings extend the evidence base, confirming these effects in a Latin American sample, a population that has seen relatively little representation in the international literature on SRL.

Moreover, in focusing particularly on low-achieving students at the end of their elementary school trajectory, implying repeated exposure to failure, the positive intervention effects obtained in our study are particularly promising. As observed by Schoenfeld (1992), and as we experienced throughout our intervention, in this particular population, tasks are addressed with little prior analysis or planning, using random solution strategies that do not respond to task requirements. Adding to this is the role played by previously acquired knowledge and skills, as confirmed by the significant effect of MPS skills at baseline on later MPS outcomes.

While the instruction of self-regulation strategies may contribute overall to the improvement of MPS, based on our data, efficiency or transfer beyond the intervention context appears to be variable.

Intervention based exclusively on Cognitive Strategy (CS) instruction contributed to improving MPS, yet its effects appeared limited to the context of the intervention, as they weakened at two months post- 
intervention as MPS scores dropped down to control group levels. Cognitive strategies are considered to be more closely related to the task and allow students with limited previous knowledge to obtain better results in contexts that require minimal transfer (Butler et al., 2005; Kramarski et al., 2013). As in previous studies, exclusive cognitive-based instruction exhibited the smallest effect sizes (Dignath et al., 2008).

Addressing cognitive strategies seems necessary, yet provides insufficient flexibility in responding to different situations (Boekaerts, 1999). These strategies were included in metacognitive and volitional intervention conditions, likely contributing to a clearer task structure. Such clarity may generate positive emotions (Schukajlow et al., 2017), better equipping students to face the task.

Instruction based on Metacognitive Self-Regulation (MCS) combined cognitive strategies with metacognitive planning, supervision and evaluation, following the typical outline of socio-cognitive models (Zimmerman, 2000). The incorporation of metacognitive regulation strategies has been directly related to mathematical competence (de Corte et al., 2011). This intervention strategy appears effective for low-achieving students in our sample, as it enhanced their MPS skills even with the passing of time. The effect size established in our study $(d=1.14)$ is similar to that reported for interventions in mathematics in primary education (Dignath et al., 2008).

The Volitional Script (VS) group combined cognitive and volitional strategies, predominantly including the strengthening of effort and concentration, disconnection of negative emotions, and impulse control (Corno, 2001). Those participating in the VS group obtained the best results in MPS, both immediately after the intervention and at two months post-intervention. The effects appear to be maintained as time passes and more transfer is required. Comparisons with the control group reach effect sizes close to $d=$ 2.00, showing the significant contribution of this intervention to improving MPS results in low-achieving students.

There is reason to believe that the instruction of volitional strategies may better suit students who have repeatedly experienced failure. Low academic achievement may elevate anxiety (Weidman et a, 2015), hinder initiative for action, and limit positive affect (Kazén et al., 2008). Volitional control strategies address motivation and emotions related to these situations. The instruction of volitional control contributes to generating a more controlled setting and a climate of security and confidence, promoting conditions that allow low-achieving students to perform (Baumann \& Kuhl, 2005). Interventions focused on student motivation are most effective when they are included in primary education interventions and promote the use of cognitive strategies (Dignath \& Büttner, 2008).

Regarding study limitations, as practical issues limited our intervention design, we were unable to involve teachers as intervention implementers, which would have been preferable. However, the interventions were designed in such a way - by modeling strategies and orienting feedback - that they could be implemented by teachers in the classroom. Nonetheless, involving teachers could raise particular implementation challenges, as explicit instruction of self-regulation in the classroom is generally scarce and not perceived as part of a teacher's role (Dignath \& Büttner, 2018).

On the other hand, this study could have been enriched by involving all students in the classroom, rather than focusing on low-achieving students. Nonetheless, as a point of departure for further research, the particular aim of this study to research the intervention impact for low-achieving students was grounded in the pressing need to address the problem of struggling students, as they hardly benefit from regular participation in the classroom. Future studies should look into the differential effects of teaching selfregulation in the classroom, accounting for students with diverse achievement levels and abilities. Furthermore, the small sample size should be taken into account when interpreting our results and retrieved effect sizes. Likewise, it should be pointed out that the criterion applied for establishing intervention fidelity ( $50 \%$ of all verbal interactions based on the script) may be considered unsuitable, particularly in applying general criteria for laboratory-like conditions. However, considering the limited evidence base on SRL produced in Latin American countries, and the embedded nature of the intervention, we do believe this study, its methodological limitations notwithstanding, constitutes a 
contribution to the field.

The mathematical problems used in this study were consistent with those commonly employed in the Uruguayan education system, known to rely more on repetitive rather than constructive practices (Picaroni \& Loureiro, 2010). Nonetheless, as the latter allow for more flexible solutions and operational complexity, they could be considered more suitable for the purposes of this study, as they require increased self-regulation.

In conclusion, the instruction of metacognitive and volitional strategies, combined with cognitive strategies, contributes to mathematical competence. The inclusion of volitional strategies appears to benefit low-achieving students in particular, when they address their affective and motivational dynamics but also cognitive strategies and the specific content of tasks.

\section{References}

Baars, M., Wijnia, L., \& Paas, F. (2017). The association between motivation, affect, and self-regulated learning when solving problems. Frontiers in Psychology, 8, 1-12.

https://doi.org/10.3389/fpsyg.2017.01346

Baez-Estradas, M., \& Alonso-Tapia, J. (2017). Training strategies for self-regulating motivation and volition: Effect on learning [Entrenamiento en estrategias de autorregulación de la motivación y la volición: efecto en el aprendizaje]. Anales de Psicología, 33(2), 292-300.

https://doi.org/10.6018/analesps.33.2.229771

Baumann, N., \& Kuhl, J. (2005). How to resist temptation: The effects of external control versus autonomy support on self-regulatory dynamics. Journal of Personality, 73(2), 443-470.

https://doi.org/10.1111/j.1467-6494.2005.00315.x

Ben-Eliyahu, A. (2019). Academic emotional learning: A critical component of self-regulated learning in the emotional learning cycle. Educational Psychologist, 54(2), 84-105.

https://doi.org/10.1080/00461520.2019.1582345

Bishara, S. (2016). Self-regulated math instructions for pupils with learning disabilities. Cogent Education, 3(1), 1-14. https://doi.org/10.1080/2331186X.2016.1262306

Boekaerts, M. (1999). Self-regulated learning: Where we are today. International Journal of Educational Research, 31(6), 445-457. https://doi.org/10.1016/S0883-0355(99)00014-2

Butler, D., Beckingham, B., \& Lauscher, H. (2005). Promoting strategic learning by eighth-grade students struggling in mathematics: A report of three case studies. Learning Disabilities Research and Practice, 20(3), 156-174. https://doi.org/10.1111/j.1540-5826.2005.00130.x

Butler, D. L., \& Schnellert, L. (2015). Success for students with learning disabilities: what does selfregulation have to do with it? In T. J. Cleary (Ed.), Self-regulated learning interventions with at-risk youth: Enhancing adaptability, performance, and well-being. APA Press.

Chatzistamatiou, M., Dermitzaki, I., Efklides, A., \& Leondari, A. (2015). Motivational and affective determinants of self-regulatory strategy use in elementary school mathematics. Educational Psychology, 35(7), 835-850. https://doi.org/10.1080/01443410.2013.822960

Cleary, T. J., \& Kitsantas, A. (2017). Motivation and self-regulated learning influences on middle school mathematics achievement. School Psychology Review, 46(1), 88-107. 
Corno, L. (2001). Volitional aspects of self-regulated learning. In B. J. Zimmerman \& D. H. Schunk (Eds.), Self-regulated learning and academic achievement: Theoretical perspectives (pp.191-225). Lawrence Erlbaum Associates.

de Boer, H., Donker, A. S., Kostons, D. D. N. M., \& van der Werf, G. P. C. (2018). Long-term effects of metacognitive strategy instruction on student academic performance: A meta-analysis. Educational Research Review, 24, 98-115. https://doi.org/10.1016/i.edurev.2018.03.002

de Corte, E., Mason, L., Depaepe, F., \& Verschaffel, L. (2011). Self-regulation of mathematical knowledge and skills. In B. J. Zimmerman \& D. H. Schunk (Eds.), Handbook of Self-Regulation of Learning and Performance (pp.155-172). Routledge.

Dignath, C., Büttner, G., \& Langfeldt, H.-P. (2008). How can primary school students learn self-regulated learning strategies most effectively?: A meta-analysis on self-regulation training programmes. Educational Research Review, 3(2), 101-129.

Dignath, C., \& Büttner, G. (2018). Teachers' direct and indirect promotion of self-regulated learning in primary and secondary school mathematics classes - insights from video-based classroom observations and teacher interviews. Metacognition and Learning, 13(2). https://doi.org/10.1007/s11409-018-9181-x

Dignath, C., \& Büttner, G. (2008). Components of fostering self-regulated learning among students. A meta-analysis on intervention studies at primary and secondary school level. Metacognition and Learning, 3(3), 231-264. https://doi.org/10.1007/s11409-008-9029-x

Donker, A. S., de Boer, H., Kostons, D., Dignath van Ewijk, C. C., \& van der Werf, M. P. C. (2014). Effectiveness of learning strategy instruction on academic performance: A meta-analysis. Educational Research Review, 11, 1-26. https://doi.org/10.1016/i.edurev.2013.11.002

Dörrenbächer, L., \& Perels, F. (2015). Volition completes the puzzle: Development and evaluation of an integrative trait model of self-regulated learning. Frontline Learning Research, 3(4), 14-36.

https://doi.org/10.14786/Flr.v3i4.179

Greene, J. A. (2015). Serious challenges require serious scholarship: Integrating implementation science into the scholarly discourse. Contemporary Educational Psychology, 40, 112-120.

https://doi.org/10.1016/i.cedpsych.2014.10.007

Greene, J. A. (2018). Self-regulation in education. Routledge.

Harding, S.-M., English, N., Nibali, N., Griffin, P., Graham, L., Alom, B., \& Zhang, Z. (2019). Self-regulated learning as a predictor of mathematics and reading performance: A picture of students in grades 5 to 8. Australian Journal of Education, 63(1),74-97. https://doi.org/10.1177/0004944119830153

Hattie, J. (2009). Visible learning: A synthesis over 800 meta-analyses relating to achievement. Routledge.

Heirweg, S., de Smul, M., Devos, G., \& van Keer, H. (2019). Profiling upper primary school students' selfregulated learning through self-report questionnaires and think-aloud protocol analysis. Learning and Individual Differences, 70, 155-168. https://doi.org/10.1016/j.lindif.2019.02.001

Huck, S. W., \& Melean, R. A. (1975). Using a repeated measures ANOVA to analyze the data from a pretestposttest design: A potentially confusing task. Psychological Bulletin, 82(4), 511-518. 
Hu, L. T., \& Bentler, P. M. (1999). Cutoff criteria for fit indexes in covariance structure analysis: Conventional criteria versus new alternatives. Structural Equation Modeling, 6(1), 1-55.

https://doi.org/10.1080/10705519909540118

Kazén, M., Kaschel, R., \& Kuhl, J. (2008). Individual differences in intention initiation under demanding conditions: Interactive effects of state vs. action orientation and enactment difficulty. Journal of Research in Personality, 42(3), 693-715. https://doi.org/10.1016/j.jrp.2007.09.005

Kim, C. M., \& Bennekin, K. N. (2013). Design and implementation of volitional control support in mathematics courses. Educational Technology Research and Development, 61(5), 793-817.

https://doi.org/10.1007/s11423-013-9309-2

Kramarski, B., Weiss, I., \& Sharon, S. (2013). Generic versus context-specific prompts for supporting selfregulation in mathematical problem solving among students with low or high prior knowledge. Journal of Cognitive Education and Psychology, 12(2), 197-214. https://doi.org/10.1891/1945-8959.12.2.197

Kuhl, J., Kazén, M., \& Quirin, M. (2014). La Teoría de la Interacción de Sistemas de la Personalidad (PSI) [The Theory of Personality Systems Interaction (PSI)]. Revista Mexicana de Psicología, 31(2), 90-99.

Leidinger, M., \& Perels, F. (2012). Training self-regulated learning in the classroom: Development and evaluation of learning materials to train self-regulated learning during regular mathematics lessons at primary school. Education Research International, (Especial Issue), 1-14.

https://doi.org/10.1155/2012/735790

Montero, I., \& León, O. (2007). Guía para nombrar los estudios de investigación en Psicología [A guide for naming research studies in psychology]. International Journal of Clinical and Health Psychology, 7(3), 847862.

OECD. (2016). PISA 2015 Results (Volume I): Excellence and Equity in Education. OECD Publishing. https://doi.org/10.1787/9789264266490-en

Op'tEynde, P., De Corte, E., \& Verschaffel, L. (2006). "Accepting emotional complexity": A socioconstructivist perspective on the role of emotions in the mathematics classroom. Educational Studies in Mathematics, 63(2), 193-207. https://doi.org/10.1007/s10649-006-9034-4

Otto, B., \& Kistner, S. (2017). Is there a Matthew effect in self-regulated learning and mathematical strategy application? Assessing the effects of a training program with standardized learning diaries. Learning and Individual Differences, 55, 75-86. https://doi.org/10.1016/i.lindif.2017.03.005

Panadero, E. (2017). A review of self-regulated learning: Six models and four directions for research. Frontiers in Psychology, 8, 1-28. https://doi.org/10.3389/fpsyg.2017.00422

Pena, M. (2005). Los nuevos problemas. La resolución de problemas en la escuela [The new problems. Problem solving in school]. Aula.

Perels, F., Dignath, C., \& Schmitz, B. (2009). Is it possible to improve mathematical achievement by means of self-regulation strategies? Evaluation of an intervention in regular math classes. European Journal of Psychology of Education, 24(1), 17-31.

Picaroni, B., \& Loureiro, G. (2010). ¿Qué matemática se enseña en las aulas de sexto año de primaria en escuelas de Latinoamérica? [What mathematics is taught in sixth-grade elementary school classrooms in Latin America?]. Páginas de Educación, 3, 29-60. 
Schlesier, J., Roden, I., \& Moschner, B. (2019). Emotion regulation in primary school children: A systematic review. Children and Youth Services Review, 100, 239-257.

https://doi.org/10.1016/i.childyouth.2019.02.044

Schoenfeld, A. H. (1992). Learning to think mathematically: Problem solving, metacognition, and sensemaking in mathematics. In D. Grouws (Ed.), Handbook for research on mathematics teaching and learning (pp. 334-370). MacMillan.

Schukajlow, S., Rakoczy, K., \& Pekrun, R. (2017). Emotions and motivation in mathematics education: Theoretical considerations and empirical contributions. ZDM - Mathematics Education, 49(3), 307-322.

https://doi.org/10.1007/s11858-017-0864-6

Schukajlow, S., \& Rakoczy, K. (2016). The power of emotions: Can enjoyment and boredom explain the impact of individual preconditions and teaching methods on interest and performance in mathematics? Learning and Instruction, 44, 117-127. https://doi.org/10.1016/j.learninstruc.2016.05.001

Schwinger, M., \& Otterpohl, N. (2017). Which one works best ? Considering the relative importance of motivational regulation strategies. Learning and Individual Differences, 53, 122-132.

https://doi.org/10.1016/j.lindif.2016.12.003

Siddiqui, N., \& Ventista, O. M. (2018). A review of school-based interventions for the improvement of social emotional skills and wider outcomes of education. International Journal of Educational Research, 90, 117-132. https://doi.org/10.1016/j.ijer.2018.06.003

Taylor, R., Oberle, E., Durlak, J., \& Weissberg, R. (2017). Promoting positive youth development through school-based social and emotional learning interventions: A meta-analysis of follow-up effects. Child Development, 88(4), 1156-1171. https://doi.org/10.1111/cdev.12864

Tzohar-Rozen, M., \& Kramarski, B. (2018). Metacognition and meta-affect in young students: Does it make a difference in mathematical problem solving? Teachers College Record, 119(13), 1-28.

Tzohar-Rozen, M., \& Kramarski, B. (2014). Metacognition, motivation, and emotions: Contribution of selfregulated learning to solving mathematical problems. Global Education Review, 1(4), 76-95.

Vandevelde, S., Van Keer, H., \& Merchie, E. (2017). The challenge of promoting self-regulated learning among primary school children with a low socioeconomic and immigrant background. Journal of Educational Research, 110(2), 113-139. https://doi.org/10.1080/00220671.2014.999363

Weidman, A. C., Augustine, A. A., Murayama, K., \& Elliot, A. J. (2015). Internalizing symptomatology and academic achievement: Bi-directional prospective relations in adolescence. Journal of Research in Personality, 58, 106-114. https://doi.org/10.1016/i.jrp.2015.07.005

Yidizli, H., \& Saban, A. (2016). The effect of self-regulated learning on sixth-grade Turkish students' mathematics achievements and motivational beliefs. Cogent Education, 3(1), 1-17.

https://doi.org/10.1080/2331186X.2016.1212456

Zimmerman, B. J. (2000). Attaining self-regulation. A social cognitive perspective. In M. Boekaerts, P. Pintrich, \& M. Zeidner (Eds.), Handbook of Self-Regulation (pp. 13-39). Academic Press. 